\title{
EVALUATING PARAMETERS OF THE PRESENT-DAY PUBLIC DISCOURSE LINGUISTIC CORRECTNESS AND COMMUNICATIVE EFFICIENCY
}

\author{
Elena I. Pochtar
}

Shevchenko State University of Pridnestrovie, Tiraspol, Pridnestrovie

\begin{abstract}
The article studies in linguo-philosophical and linguo-communicative angles the problem of speech ecology in the conditions of the present-day society along with the violations, caused by it, of linguistic and communicative norms of cooperative speech intercourse. Proceeding from the language-as-a-doer conception and also from the fact of limited linguistic censorship in the sphere of present-day mass communication, the author justifies possibility of all kinds of irregularities in public discourse and analyses how their appearance can affect the eventual communicative efficiency of the discourse as a whole. The article gives a chronological observation of the practice of discourse analysis acquiring the four basic criteria of evaluating linguistic utterances - grammaticality, acceptability, truth, and reference - which were gradually introduced in linguistics as the result of influence from adjacent areas of knowledge. On the basis of selected examples the author tries to find out whether appliance of these speech evaluation methods is justified inasmuch as they help to evaluate linguistic conventions implementation and ability of speech utterances to transmit communicator's intentions implicated in them. Having studied different kinds of speech deviations violating, to this or that extant, the norms of grammar, syntax, conceptualization processes, and communication canons, the author comes to the conclusion that violations of norms do not always cause ultimate communicative failures. According to the author, verbal communication can only be estimated as unsuccessful when it fails to receive adequate perception on the part of the addressee. Based on that, the conclusion is made that while evaluating discourse linguistic correctness and pragmatic consistency, one should, first of all, consider peculiarities of the extra-linguistic context and the category of the receptive audience rather than whether the discourse does or does not conform to the norms of usage and standard speech ethics.

Key words: public discourse, linguistic standardness, speech ecology, cooperative communication, speech deviances, communicative deviations, communicative efficiency, extra-linguistic context in communication.

Citation. Pochtar E.I. Evaluating Parameters of the Present-Day Public Discourse Linguistic Correctness and Communicative Efficiency. Vestnik Volgogradskogo gosudarstvennogo universiteta. Seriya 2. Yazykoznanie [Science Journal of Volgograd State University. Linguistics], 2020, vol. 19, no. 6, pp. 134-147. (in Russian). DOI: https://doi.org/10.15688/jvolsu2.2020.6.10
\end{abstract}

УДК 81 '42:82.085.2

Дата поступления статьи: 27.03.2020

ББК 81.055 .1 Дата принятия статьи: 14.09.2020

\section{ПАРАМЕТРЫ ОЦЕНКИ ЯЗЫКОВОЙ КОРРЕКТНОСТИ И КОММУНИКАТИВНОЙ УСПЕШНОСТИ СОВРЕМЕННОГО ПУБЛИЧНОГО ДИСКУРСА}

\section{Елена Ивановна Почтарь}

Приднестровский государственный университет им. Т.Г. Шевченко, г. Тирасполь, Приднестровье

Аннотация. В статье в лингвофилософском и лингвокоммуникативном ракурсах рассматривается проблема речевой экологии в условиях современного социума и обусловленные ею нарушения лингвистических и коммуникативных норм кооперативного речевого общения. Исходя из концепции деятельностной сущности языка, а также ограниченности лингвистической цензуры в сфере современной массовой коммуникации, 
автор обосновывает неизбежность возникновения иррегулярности в публичной речи и показывает возможности их влияния на конечную коммуникативную успешность дискурса в целом. Дается хронологическое описание путей возникновения в практике дискурсивного анализа четырех базовых критериев оценки корректности языковых построений: грамотности, приемлемости, истинности и референтности, последовательно сформировавшихся в языкознании под влиянием смежных с лингвистикой областей знания. С опорой на конкретные примеры характеризуется оправданность применения этих способов оценки речи как с точки зрения соблюдения языковых конвенций, так и с учетом способности речевых высказываний транслировать имплицированные в них интенции коммуникатора. В результате исследования различные виды речевых девиаций, нарушающих нормы грамматики, синтаксиса, процедур концептуализации и канонов коммуникации, автор приходит к заключению, что не всякое нарушение нормы провоцирует коммуникативную неудачу. Продемонстрировано, что однозначно неуспешной может считаться лишь вербальная коммуникация, не получающая адекватной перцепции со стороны адресата. На основании этого делается вывод о том, что оценивание дискурса на предмет его лингвистической корректности и прагматической состоятельности следует делать не столько исходя из его соответствия узусу и эталонной речевой этике, сколько с учетом специфики околоязыкового контекста и характера рецептивной аудитории.

Ключевые слова: публичный дискурс, языковая нормативность, речевая экология, кооперативное общение, речевая девиация, коммуникативная девиация, коммуникативная успешность, внеязыковой контекст коммуникации.

Цитирование. Почтарь Е. И. Параметры оценки языковой корректности и коммуникативной успешности современного публичного дискурса // Вестник Волгоградского государственного университета. Серия 2 , Языкознание. -2020. - Т. 19, № 6. - C. 134-147. - DOI: https://doi.org/10.15688/jvolsu2.2020.6.10

\section{Введение}

Обращаясь к наиболее острым проблемам современных социумов, следует констатировать, что под воздействием множества этнокультурных, геополитических, экономикоправовых и техногенных факторов, активно определяющих сегодня состояние коммуникационной сферы, публичная речь и речевая культура в целом претерпевают серьезные качественные сдвиги, очевидно требующие корректировки параметров их оценки.

В трактовке А.П. Сковородникова культура речи в широком смысле есть «нормы и компетенции речевого общения в их совокупности», или, более детально, «оптимальная организация речи, ее коммуникативная эффективность и соответствующие компетенции языковой личности» (цит. по: [Копнина, Еремина, 2015, с. 23]). В таком определении культура речи максимально сближается с экологией речи, включающей, помимо понятия текущего состояния языка и речи в среде их функционирования, также и понятие последствий влияния этой среды на их системность и нормативность.

Серьезность и множественность проблем в сфере языковой и речевой экологии акцентируются в научных публикациях ряда отечественных ученых [Кезина, 2016; Копнина,
Еремина, 2015; Майорова, 2016; Сковородников, 2008; Усанова, 2010; и др.].

Современная речевая ситуация претерпевает кардинальные изменения под воздействием целого ряда специфических экстралингвистических факторов, обусловленных текущим состоянием и в целом динамикой развития социума. К таким факторам прежде всего относится наблюдаемое сегодня значительное расширение спектра социальных групп, вовлеченных в публичную коммуникацию. Категории участников в ней практически не ограничены сегодня ни возрастом, ни образованием, ни профессиональной принадлежностью, ни религиозными верованиями, ни какими-либо другими параметрами социального статуса личности. Одновременно с массовостью участия в нем различных групп коммуникаторов публичный дискурс демонстрирует стремительное увеличение разнообразия его разновидностей - политический, юридический, деловой, психолого-педагогический, научно-просветительский, а также форм манифестации, включающих сегодня, кроме традиционных выступлений, лекций и дискуссий, интернет-блоги, твиты, посты и др. Фактическое отсутствие цензуры в сфере публичной массовой коммуникации выступает в качестве еще одного важного фактора, провоцирующего определенную вольность коммуникаторов 
в их выборе форм выражения мыслей и суждений, освобождающего их от необходимости быть сдержанными, осторожными и ответственными в своем речевом поведении. Все эти факторы в совокупности не только оказывают влияние на среду функционирования языка и речи, но и формируют языковое сознание социума, определяющее в свою очередь состояние языка и речи, появление новых лингвистических реалий, зеркально отражающих изменившиеся условия экстралингвистической среды. В некоторых важнейших направлениях, которые задают основополагающие условия существования общества, происходили и до сих пор происходят содержательные трансформации, в результате которых возникают новые или радикально изменяются уже имеющиеся коммуникативные инструменты [Кушнерук, 2018, с. 18].

К негативным последствиям этих «содержательных трансформаций» следует отнести так называемую «либерализацию» речи, или, по сути, ее «вульгаризацию», то есть резкое снижение уровня речевой культуры и, как следствие, деградацию языка и речи, деформацию существующих норм и традиций, появление разного рода языковых и речевых иррегулярностей, некорректных тактик и приемов ведения коммуникации. Одной из форм негативного влияния среды на речевое поведение социума А.П. Сковородников считал так называемое «языковое насилие», под которым он понимал «не аргументированное вовсе или недостаточно аргументированное открытое или скрытое (латентное) вербальное воздействие на адресата, имеющее целью изменение его личностных установок (ментальных, идеологических, оценочных и т. д.) или его поражение в полемике - в пользу адресата» [Сковородников, 1997, с. 10].

Ярко выраженной демонстрацией «языкового насилия» в публичном речевом поведении сегодня являются присущие ему агрессивность, безапелляционность, демагогичность, стремление к навязыванию определенных взглядов и идеологических позиций. Такие прагматические установки, реализуемые через дискурс, неминуемо провоцируют в коммуникаторе стремление уйти от существующих языковых стандартов и традиционных культурно-речевых компетенций, приводя его в итоге к полному или частичному нарушению базовых конвенций и общепринятых норм публичной речевой коммуникации.

Многие отечественные ученые-лингвисты в последние годы активно занимаются проблемами изменчивости дискурса под влиянием социальных и социокультурных факторов, изучают характер возникающих при этом трансформаций в части форм и методов организации языкового материала, его стилистического оформления и коммуникативного представления [Леонтьев, 2016; Сиротинина, 2001; Фортунатов, Бокова, 2014; Ilyinova, Kochetova, 2016; и др.].

Признавая определяющую роль околоязыкового пространства при оценке современного состояния речевой культуры, степени ее нормативности и приемлемости, нельзя ограничиваться лишь сугубо лингвистическими параметрами коммуникации, подверженной воздействию социальной среды. Не менее важным фактором выступает и собственно речевая ситуация, то есть характер адресатов, выбранные время и место общения, в совокупности определяющие задачи коммуникацией и, следовательно, влияющие на подбор речевых моделей их реализации. Очевидно, что стилистико-содержательная организация речи может быть высокоэффективной в одной ситуации общения и совершенно безуспешной - в другой, даже при условии соблюдения в ней всех языковых норм.

Значительно изменившиеся за последние десятилетия социально-нравственные и психолого-этические основы речевого поведения, его мотивы и целеполагания в рамках публичного дискурса требуют от лингвистов обсуждения актуальности и правомочности применения к реалиям существующего коммуникационного пространства стандартных критериев оценки речевой коммуникации, традиционно используемых в процессе дискурсивного анализа.

\section{Диахронический аспект проблемы оценки речевой коммуникации}

Определение, данное В. фон Гумбольдтом языку как «духу народа» [Гумбольдт, 1984], способствовало появлению в языкознании традиции исследования форм и фактов 
языка с акцентом на ключевой роли человека говорящего. Изучаемая с такой позиции речь рассматривается как вербальная экспликация социальной среды говорящего, отражение его концептосферы, культурного кода, личностной индивидуальности.

Тот факт, что перемены, постоянно происходящие внутри социумов и в жизненных пространствах индивидов, неминуемо вызывают трансформации в области их речевых традиций, дает В. фон Гумбольдту основание охарактеризовать язык как «постоянную работу духа» [Гумбольдт, 1984] и ввести в языкознание концепцию деятельностной сущности языка. В рамках этой концепции речь понимается не как механическое активирование говорящим уже имеющихся языковых моделей, а как процедура языкотворчества, создания речевых форм непосредственно в процессе вербальной деятельности человека.

Признание за языком его динамического и творческого характера, в свою очередь, выводит на передний план проблему речевых вариаций, а вслед за ними - и речевых девиаций, или иррегулярностей, возникающих в вербальной коммуникации вследствие конфликта вариативных речевых практик с жестко регламентированными языковыми нормами.

Использовавшийся в социологии термин «девиация», или «девиантность», - нарушение установленных социумом регламентов - постепенно получает широкое применение в смежных областях знания, таких как медицина, психология, педагогика.

В лингвистическую сферу понятие языковой девиации входит в 70-е гг. ХХ в. вслед за теорией трансформационной, или генеративной, грамматики Н. Хомского, первоначально возникшей для описания механизмов синтаксиса и затем распространившейся на область фонологии, морфологии, словообразования и семантики [Chomsky, 1957].

В современной дискурсологии понятие девиации приобретает еще более широкие границы и применяется относительно всех случаев неуспешной коммуникации, в которых эксплицированная семантика вербального текста входит в противоречие с изначально заданными, имплицитными по своей сути, прагматическими установками. В кооперативном общении, по П. Грайсу, главным условием ус- пешности коммуникативного акта является наличие между адресантом и адресатом согласия, или согласованности, в том, как первым (адресантом) порождается речевой конструкт, и в том, как он воспринимается его адресатом. Разбалансированность этого процесса ведет к тем или иным формам коммуникативных девиаций.

Как и все иные виды речевых иррегулярностей, коммуникативные девиации могут быть следствием влияния множества объективных и субъективных факторов. К базовым составляющим коммуникативного акта, определяющим его успешность (либо не-успешность), относятся в первую очередь личность адресанта, порождающего речь, и личность адресата, воспринимающего ее, вкупе с их физическим, психологическим, когнитивным и эмоциональным состоянием в момент общения, а также избранным каналом коммуникации.

Исходя из основных положений теории речевых актов, главным условием успешного осуществления речевой коммуникации является реализация заданного коммуникативного назначения, говорящий добивается при этом от адресата не только желаемого результата, но, что не менее важно, готовности «опознать его [говорящего] намерение получить этот результат» [Серль, 1986, с. 163]. Иными словами, в процессе коммуникации говорящий может рассчитывать на успех лишь в случае, если используемые им речевые высказывания способны транслировать слушающему весь комплекс имплицированных в них семантико-прагматических смыслов. Соответственно, коммуникативно успешным становится тот иллокутивный акт, в котором интенциональная и конвенциональная составляющие находятся в балансе, необходимом и достаточном для того, чтобы адресат понял то, что имеет в виду адресант, используя при этом языковые средства и модели, способные, в соответствии с существующими языковыми нормами, передавать значения, отражающие коммуникативные намерения адресанта [Серль, 1986, с. 163].

Очевидно, что нарушение этого прямого баланса между тем, что хочет сказать говорящий, и тем, что фактически понимает слушающий, влечет за собой разного рода коммуникативные неудачи, непонимания, недопонимания, недоразумения и иные 
формы языковых и коммуникативных девиаций. Как уже отмечалось выше, их главная причина состоит в отсутствии согласованности и взаимопонимания между непосредственными участниками коммуникации, что в свою очередь может быть спровоцировано множеством негативных факторов объективного и субъективного характера. Из субъективных самыми распространенными являются: отсутствие у одной из сторон потребности в общении; неспособность обеих либо одной из сторон к эмпатии, восприятию внутреннего мира собеседника; нежелание или неготовность слушающего вникнуть в коммуникативный замысел (интенцию) собеседника; неспособность говорящего успешно варьировать языковые формы в процессе представления конкретного дискурсивного события; незнание участниками общения норм этикетного языкового поведения или нежелание придерживаться их и ряд других факторов.

Среди объективных причин коммуникативных девиаций можно отметить возникновение разного рода внешних обстоятельств, не зависящих от коммуникаторов, при этом неблагоприятно влияющих на процесс интеракции: вмешательство третьих лиц, погодные условия и др.

Исследуя процедуры порождения и восприятия коммуникативных девиаций на материале текстов художественных произведений, Ф.С. Бацевич выделяет три типа условий коммуникативной успешности либо не-успешности речи: 1) связанные с внешними (неязыковыми) аспектами порождения и восприятия речи; 2) связанные с лингвистическими аспектами порождения и восприятия речи (которые подразделяются на два подвида: касающиеся семантики и синтактики используемых языковых средств и имеющие отношение к коммуникативному смыслу этих языковых средств); 3) связанные с прагматическим аспектом организации и функционирования используемого речевого жанра [Бацевич, 2014].

Далее рассмотрим, насколько эти виды условий успешной коммуникации согласуются с традиционно применяемыми в практике лингвистического анализа критериями оценки дискурса.

\section{Эволюция подходов к проблеме оценки дискурса}

В современной традиции дискурсивного анализа, как известно, применяются четыре основных параметра оценки языковых высказываний в процессе вербальной коммуникации: грамотность, приемлемость, истинность и референтность. Несмотря на неоспоримую обоснованность всех четырех критериев на сегодняшний день, в эволюционном плане каждый из них прошел свой путь, имел свою аргументацию и свои предпосылки, в целом отражающие ход развития языкознания в области оценки речевых построений в структуре дискурса.

Так, на этапе существования в науке идиллического представления о строгом соответствии речи теоретическим канонам языка единственным и незыблемым критерием оценки речи была ее грамотность (grammaticality), или грамматическая правильность, понимавшаяся в традициях Н. Хомского как совокупность лингвистической компетентности говорящего и речевого контекста.

По мере укрепления антропоцентрического вектора в процессе развития лингвистики и продвижения трансформационных теорий критерий грамотности уступает место более «лояльному» параметру оценки речевой коммуникации - приемлемости (acceptability).

Понимаемая как допустимость использования определенных языковых построений, их уместность с точки зрения говорящего в конкретном речевом контексте, приемлемость демонстрирует тенденцию к оцениванию речи в социолингвистическом аспекте, поскольку определение приемлемости тех или иных высказываний обусловлено субъективным восприятием непосредственных участников коммуникации.

Анализ эволюции научного подхода к нормативности речевых практик показывает, что критерий приемлемости возникает как следствие включения в лингвистическую сферу философской категории истинности ложности, что в свою очередь подтверждает наличие тесной взаимосвязи между языковыми и общефилософскими явлениями и понятиями.

С возникновением в лингвистике альтернативного направления трансформационной 
грамматики - генеративной семантики, центральным понятием которой становится философская категория истинности (truth), при дискурсивном анализе для оценки речевых высказываний стал применяться этот параметр [Chomsky, 1965; Lakoff, 1971; McCawley, 1968; Mates, 1975]. Так возникает традиция определения правильности речи через установление правдивости транслируемой в ней информации, соответствия сказанного реально существующему.

Стремление приверженцев лингвофилософского подхода к языку и речи рассматривать семантические явления с позиций логических правил способствовало тому, что в лингвистический анализ был введен еще один философский параметр - референтность (reference). Выступая как маркер эквивалентности языковой единицы и номинируемого ею объекта реальности, категория референтности, с одной стороны, расширила горизонты дискурсивного анализа, позволив взглянуть на речь с учетом сохранения в ней тех самых пресуппозиций, которые, по Дж. Серлю, представляют собой ключевые условия успешной коммуникации. С другой стороны, введение категории референтности усилило степень субъективности оценки речи, дало возможность рассматривать ее не столько с позиции узуса, сколько с позиций того, что фактически имел в виду говорящий в конкретном речевом контексте.

Таким образом, развиваясь в русле общих тенденций лингвофилософии и теории коммуникации, дискурсивный анализ последовательно приобретает четыре параметра оценки фактов языка в составе коммуникативного акта - грамотность, приемлемость, истинность и референтность. С опорой на эти параметры можно успешно выявлять не только языковую, но и, что гораздо сложнее и важнее, коммуникативную успешность либо девиантность отдельных речевых интеракций и целых дискурсов. Коммуникативная успешность речи в свою очередь может свидетельствовать о высоком уровне культурно-речевой компетентности говорящего, позволяющей ему эффективно актуализировать, а слушающему декодировать заданные семантикопрагматические смыслы, и в конечном счете успешно реализовывать исходные интенции.
Разбалансированность же взаимосвязи между смысловым содержанием и прагматическими установками, с одной стороны, и эксплицирующими их языковыми средствами и стилевыми решениями, с другой, свидетельствует о низком уровне речевой компетентности коммуникатора и выступает основной причиной его коммуникативных неудач.

\section{Дискурсивные аномалии, провоцирующие коммуникативные неудачи}

Рассмотрим на примере англоязычных высказываний различные виды языковых и коммуникативных девиаций и проанализируем причины, которые привели к тому, что они оказались коммуникативно неуспешными.

Возьмем за основу шесть речевых построений, содержащих те или иные формы языковых и/или коммуникативных иррегулярностей:

(1) In just an hour she will.

(2) The woman left him after a few days with who he was in love.

(3) Peter the Great was the most progressivelyminded king in the history of Russia.

(4) All people love jazz.

(5) The train's tail went deep into the ground.

(6) Every bird likes its own nest.

Как видно из приведенных примеров, в высказываниях (1) и (2) нарушения затрагивают структурные и семантические языковые нормы, высказывания (3)-(6) согласуются с англоязычным грамматическим узусом, но противоречат канонам коммуникации в силу недостоверности содержащейся в них информации либо неадекватности формы ее концептуализации.

Проанализируем детально каждую из шести представленных выше девиаций.

(1) In just an hour she will.

В этом высказывании легко обнаруживается нарушение структурно-семантической нормативности, так как в нем отсутствует часть сказуемого и, возможно, обстоятельственного элемента, что провоцирует смысловую незавершенность, неясность и, следовательно, 
коммуникативную несостоятельность всего высказывания: In just an hour she will... (do what?).

Введение в высказывание (1) нормативно обязательного смыслового глагола, например In just an hour she will come, а также обстоятельства, например In just an hour she will come here, могло бы трансформировать это высказывание в структурно законченное и семантически полное. В свою очередь, оформленное согласно узуально стандартным языковым параметрам, такое высказывание создало бы коммуникативно успешный речевой акт, адекватно эксплицирующий интенции говорящего.

(2) The woman left him after a few days with who he was in love.

Пример содержит еще одну разновидность языковой аномалии - нарушение типичного для английского языка порядка слов: определительное придаточное предложение неправомерно отделено от определяемого слова, вследствие чего нарушена логическая последовательность смысловых синтагм.

Очевидно, что придаточное предложение who he was in love with должно следовать сразу за определяемым словом The woman, организуя все смысловое единство следующим образом: The woman, who he was in love with, left him after a few days.

Таким образом, примеры (1) и (2) демонстрируют отклонения от грамматических норм английского языка и, следовательно, нарушение оценочного параметра грамотности, влекущее за собой коммуникативную неудачу, связанную с лингвистическими аспектами порождения и восприятия речи, а именно с ее семантикой и синтактикой.

Критерии приемлемости и истиннос$m u$ в силу того, что не имеют прямого отношения к грамматическим конвенциям языка, но определяют степень корректности соотнесения лингвистических единиц с объектами неязыковой среды, в большей мере связаны с прагматическим аспектом коммуникации.

Так, принцип приемлемости основывается на двух одинаково важных компетенциях коммуникаторов: умении говорящего кодировать средствами языка окружающую действительность, корректно используя при этом соответствующие узусу языковые единицы, и способности слушающего адекватно декодировать из этих речевых построений имплицированные в них смысловые послания. Тот факт, что, как уже отмечалось выше, приемлемость использования тех или иных речевых единиц определяется самим коммуникатором, делает этот критерий субъективным, поскольку он в значительной мере зависит от лингвистической и экстралингвистической компетентности говорящего. Тем не менее в условиях кооперативного общения соответствие речи параметру приемлемости является важным условием успешности речевой коммуникации.

(3) Peter the Great was the most progressivelyminded king in the history of Russia.

В приведенном примере представлено высказывание, оформленное грамотно и корректно согласно нормам языка, однако неприемлемое с точки зрения стандартов коммуникации, поскольку содержит девиацию в части языкового кодирования экстралингвистических реалий: Петр Великий назван королем России, что не соответствует нормативно принятой номинации титула, присваивавшегося в дореволюционной России правящему монарху. Для соблюдения принципа приемлемости в высказывании (3) языковая единица king должна быть заменена на $t s a r$. Более того, при всей безусловности выдающихся реформаторских заслуг Петра Первого для России в ее истории были и другие монархи, инициировавшие в высшей степени прогрессивные и эпохальные по масштабам государственные реформы. Следовательно, утверждение о том, что Петр Великий был самым прогрессивно-мыслящим королем / царем России, не соответствует истине, нарушая тем самым принцип истиннос$m u$, согласно которому речевое высказывание должно быть прямым и точным отражением объективно существующих реалий.

Таким образом, тесно связанный с приемлемостью критерий истинности в еще большей степени ориентирован на околоязыковой контекст коммуникации, так как основной его функцией является оценивание точности концептуализации средствами языка фактов объективной действительности.

(4) All people love jazz. 
В высказывании продемонстрирована аномалия в соблюдении критерия истинности, поскольку постулируемая информация очевидно идет вразрез с истиной, так как далеко не все люди любят джаз. Для того чтобы исправить неточность этого утверждения, приведя его в соответствие с параметром $u c$ тинности, необходимо внести как грамматические, так и контекстуальные коррективы. Погруженное в контекст конкретной жизненной ситуации, например в среду концертного зала, где проходит джазовый концерт и все люди восторженно аплодируют исполнителям, это высказывание могло бы звучать в устах одного из присутствующих следующим образом: All the people love jazz. Изменение грамматической конструкции высказывания путем добавления определенного артикля the будет способствовать тому, что эксплицируемый им контингент людей, любящих джаз, сузится до конкретной аудитории этого концертного зала и тем самым, с учетом факта бурных аплодисментов всех присутствующих, сделает возможным считать высказывание «все эти люди любят джаз» соответствующим реальной действительности. Соблюдение параметра истинности исключит возможность коммуникативной неудачи, связанной с нарушением норм прагматической организации речи.

Говоря о критериях приемлемости и истинности, следует отметить, что в рамках интерактивного общения они довольно тесно переплетены, вследствие чего нарушение одного из них, как правило, влечет за собой коммуникативную девиацию и в части другого, например:

(5) The train's tail went deep into the ground.

Сказанное в данном случае является ложным и по сути (в реальном мире невозможно, чтобы «хвост поезда уходил глубоко в землю»), и в плане адекватности смыслового прочтения в целом, поскольку в концептуальном сознании интерпретатора отсутствуют ментальные опоры, позволяющие естественно декодировать представленную в этом высказывании ситуацию. Таким образом, в предложении (5) содержатся аномалии и в части соблюдения параметра истинности эксплицированной в речевом акте информации, и в части критерия приемлемости использованного в нем способа концептуализации реального контекста.

Как видно из приведенных выше примеров (3) и (4), характер оценки норм коммуникации, заложенный в параметрах приемлемости и истинности, выводит анализ дискурса из горизонтальной плоскости соблюдения правил грамматики в вертикальную плоскость соответствия содержащихся в речи семантических и семантико-прагматических смыслов существующим экстралингвистическим реалиям. Таким образом, критерии приемлемости и истинности обеспечивают исполнение речью ее важной коммуникативной функции - адекватной манифестации пропозиционального и информационного содержания использованных в ней языковых средств.

Не менее существенным в оценке семантико-прагматической организации речи и определении успешности взаимодействия в ней узуальных и актуальных семантических и коммуникативных смыслов является критерий референтности, призванный обеспечить соответствие речевых построений актуализируемым ими концептам на более глубоком уровне, нежели это определяется в случаях с приемлемостью и истинностью.

В отличие от этих двух критериев, основанных преимущественно на объективной оценке степени соответствия фактов языка существующей реальности, референтность как категория дискурсивного анализа предполагает оценку речи посредством таких субъективных факторов, как цели, замыслы и намерения непосредственных участников коммуникации, а также учет специфики контекстных и ситуативных условий общения.

Так, высказывание (3) Peter the Great was the most progressively-minded king in the history of Russia перестает быть девиантным при анализе его через индивидуальную оценочную позицию говорящего, вероятно считающего, что Петр Первый действительно был самым прогрессивным монархом в истории России. Аналогично можно рассмотреть и высказывание (4) All people love jazz, возможно актуализирующее субъективную пресуппозицию говорящего, одержимого джазом и искренне считающего, что все люди без исключения любят джаз. 
Изначальное стремление коммуникатора предложить свой вариант «объективной реальности», основанный на его личной «картине мира», делает высказывания референтноадекватными и по этой причине дискурсивнодопустимыми. Однако возможно ли считать их истинными и, следовательно, конвенционально состоятельными коммуникативными актами и какова степень прогнозируемой успешности такого высказывания в процессе интеракции?

Как уже отмечалось, достоверность постулируемых речью смыслов и фактов является одним из базовых принципов организации ее содержательного пространства. По утверждению профессора Я. Хинтикка, выраженное средствами языка не должно оставлять сомнения в том, что мир настолько таков, насколько сказанное в предложении можно считать истинным [Hintikka, 1971, p. 161].

Однако фактическое достижение информационной достоверности в речевом высказывании осложняется тем, что, как было продемонстрировано на примере (4), параметры оценки содержания коммуникативного послания в значительной степени зависят от того, в каком качестве оно актуализируется и воспринимается.

Очевидно, что, если рассматривать высказывание как самостоятельное коммуникативное целое в его структурно-смысловой завершенности, вне связи с околоязыковой средой дискурса, оно в большей степени располагает к оценке с позиции истинности и приемлемости. В случае же когда вербальное высказывание становится полноценным элементом дискурса, включающего как объективные, так и субъективные факторы речетворчества, корректность его прочтения и нормативной категоризации оказываются полностью зависящими от внеязыкового контекста существующего коммуникативного пространства. Например:

(6) Every bird likes its own nest.

Как самостоятельная речевая единица это высказывание может восприниматься в качестве стандартного с точки зрения его языковой грамотности, но будет спорным с позиции истинности, поскольку широко извест- но, что не все птицы предпочитают собственные гнезда, более того, существуют виды птиц, которые не вьют гнезд. Однако, если применить к этому утверждению правило референтности и оценить его с позиции дискурса, итог будет иным. В своем идиоматическом значении это высказывание соответствует русской идиоме Всяк кулик свое болото хвалит и, следовательно, транслирует послание, никак не связанное с птицами, но характеризующее некий субъект как предвзятый и необъективный в своих суждениях. В таком качестве это утверждение перестает быть девиантным с точки зрения соблюдения критериев истинности и приемлемости.

Очевидно, что оценка нормативности высказывания как коммуникативной единицы, способной адекватно реализовать заданную прагматическую установку, возможна лишь при наличии паралингвистического контекста, проясняющего особенности концептуализации реалий в конкретном речевом высказывании с учетом конкретной дискурсивной ситуации. Так, высказывание (6) Every bird likes its own nest в качестве отдельно взятой речевой единицы, вне контекста, не может считаться транслирующей достоверную информацию с точки зрения норм коммуникации. В то же время, будучи включенным в дискурс, то есть погруженным в контекст, это высказывание приобретает информационную приемлемость, концептуальную достоверность и, следовательно, может быть коммуникативно успешным. Например, You can hear her telling now and again how great her native town is - every bird likes its own nest. B таком виде высказывание (6) Every bird likes its own nest транслирует свое истинное, идиоматическое значение, легко декодируемое благодаря контексту.

Возвращаясь к проблеме оценки разных аспектов нормативности речевых построений, способствующих в конечном счете их коммуникативной успешности, следует заключить, что универсального подхода к этой проблеме и ее однозначного решения не существует.

В то время как параметр грамотности, имеющий четко определенные формальные границы, позволяет с высокой степенью точности идентифицировать имеющиеся в речи аномалии и предупредить их в целях построе- 
ния успешной коммуникации, параметры приемлемости, истинности и референтности в силу их неоднозначности и субъективности делают невозможной категоричную оценку речи как правильной либо неправильной.

Не менее сложной оказывается задача определения достоверности информации, манифестируемой речью. Как показал анализ примеров (3), (4) и (6), одно и то же высказывание может считаться одновременно ложным и истинным, в зависимости от того, погружено оно в соответствующий контекст или нет. Иными словами, оценивать корректность вербально представленной информации возможно лишь в рамках дискурса, поскольку, как известно, только в нем языковая единица приобретает коммуникативное значение [Droste, 1977; Linsky, 1969; Marcus, 1971].

Только через установление взаимосвязи между околоязыковым контекстом, личностью коммуникатора и собственно речевым высказыванием возможно с высокой степенью точности установить, насколько корректна речь и выраженная в ней информация.

Наличие контекста и полнота имплицируемой за счет него информации создают еще одно преимущество для дискурса - он может «позволить себе» быть вербально экономичным в силу того, что важные для выполнения коммуникативной задачи смысловые и прагматические послания могут быть размещены в его околоязыковом пространстве.

Зависимость оценки речи от ее нелингвистического контекста становится еще более очевидной при попытке определения успешности речевого высказывания как акта коммуникации. Будучи составной частью кооперативного общения, дискурс не должен быть подвергнут оцениванию с учетом его рецептивной аудитории, в конечном счете определяющей степень коммуникативной успешности сказанного. В свою очередь, речевое высказывание, рассматриваемое через призму оценки со стороны адресата, может оказаться коммуникативно успешным, хотя оно нарушает несколько или все из вышеназванных параметров. В случае если речевая компетентность рецептивной аудитории находится на том же уровне, что и у говорящего, то есть имеются одинаковые для обеих сторон представления о языковых и коммуникатив- ных нормах, любая интеракция будет коммуникативно успешной даже при наличии в ней тех или иных девиаций с точки зрения узуса. И наоборот, абсолютно корректная согласно всем параметрам оценки речь может оказаться коммуникативно неуспешной, в случае если ее адресатом будет человек с недостаточным уровнем культурно-речевой компетентности. Так, иностранцу, обладающему ограниченными знаниями о России, будет гораздо понятнее и психологически комфортнее высказывание Peter the Great was the most progressivelyminded king in the history of Russia, чем аналог этого высказывания с лексемой tsar вместо king и артиклем $a$ перед ней.

Таким образом, основным итогом анализа высказываний в рамках публичного дискурса и в условиях кооперативного общения является положение об отсутствии в этой сфере единообразных, универсальных критериев оценки языковой корректности и коммуникативной успешности речевых построений.

\section{Заключение}

Выявленная неоднозначность подходов к оцениванию публичного дискурса, его зависимость от множества объективных и субъективных факторов делают проблему определения языковой правильности в сфере публичной коммуникации не имеющей конкретного, однозначного решения. Если при оценке дискурса с точки зрения корректности используемых языковых средств можно говорить о существовании относительно оправданных и достоверных критериев установления нормативности, то при определении успешности либо не-успешности речи как коммуникативного акта эта задача становится практически неразрешимой. Причина того состоит в тесной взаимосвязи между коммуникатором и реципиентом как сторонами общения, при которой главным условием успешности интеракции является способность адресанта донести до адресата транслируемую информацию в таком виде, чтобы она смогла вызвать в нем определенную, желаемую перцепцию. При этом соответствие используемых в коммуникации речевых построений узусу далеко не всегда значимо или даже необходимо, ибо важнейшее ее условие возможности для речевой 
интеракции стать коммуникативно успешной наличие у рецептивной стороны тех же стандартов ведения вербальной коммуникации, каковыми оперирует и сторона транслирующая. Иными словами, адресант может рассчитывать на успех со стороны адресата в случае, если этико-речевые стандарты обеих сторон общения совпадают. По этой причине узуально корректная речь будет способствовать успешной коммуникации лишь при условии, что ее рецептором также выступит носитель нормативной речевой культуры, и наоборот, окажется неуспешной, если будет адресована рецептору с трансформированными речевыми компетенциями. Именно этим, главным образом, объясняется тот факт, что в современном публичном дискурсе так часто реализуются те или иные формы лингвостилевых девиаций - они отражают и в полной мере соответствуют этико-речевым «стандартам» и ожиданиям целевых аудиторий.

Возвращаясь к поднятым в начале статьи проблемам культуры речи и речевой экологии, необходимо отметить, что лингвокоммуникативные «болезни», с горечью и тревогой констатируемые сегодня учеными в сфере публичной коммуникации, фактически являются естественным результатом существования тесной взаимосвязи между двумя сторонами речевого общения. В условиях, когда основная масса рецептивных коллективов не владеет канонической речью и не считает ее эталонной в принципе, более того, рассматривают ее стандарты как излишние и бессмысленные, поскольку они противоречат главной, по их мнению, задаче современной коммуникации - быть информативной, соблюдение стилистико-языковых норм перестает быть коммуникативным императивом. Стремясь максимально эффективно взаимодействовать с рецептивным сообществом, ориентированным на такие задачи коммуникации, публичный дискурс вынужден целенаправленно нарушать те или иные этико-речевые каноны, организуя свое семантико-стилевое содержание таким образом, чтобы быть в первую очередь доступным, современным, привлекательным и востребованным для реципиентов. В результате такой игры «в поддавки» с целевыми аудиториями, публичный дискурс наполняется все большим количеством девиаций, осознанно имплементируе- мых коммуникатором с целью реализации его прагматических интенций. Негативным последствием этого для речевой экологии в целом является как дальнейшее закрепление в сознании рецептивных коллективов уже существующих потребностей в лингвокоммуникативных иррегулярностях, так и, что еще опаснее, формирование у начинающих участников публичного вербального общения запроса на такие «анти-стандарты» его построения.

В этом, по нашему мнению, кроется одна из серьезнейших угроз для всей сферы современной публичной коммуникации, ибо нарушения границ языковой нормативности и речевой этики, столь позволительные и привлекательные сегодня в сиюминутном стремлении добиться более успешного и эффективного общения, в долгосрочной перспективе могут привести к разрушению фундаментальных основ самого национального языка, равно как и неразрывно связанных с ним национальной культуры и национальной идентичности.

\section{СПИСОК ЛИТЕРАТУРЫ}

Бацевич Ф. С., 2014. Коммуникативные девиации и условия успешности речевого жанра // Жанры речи. № 1-2 (9-10). С. 16-21.

Гумбольдт В. фон, 1984. Избранные труды по языкознанию. М. : Прогресс. 400 с.

Кезина С. В., 2016. Экологическая функция языка и духовная семантика слова // Экология языка и речи : материалы V Междунар. науч. конф. (Тамбов, 3-5 нояб. 2016 г.). Тамбов : ПринтСервис. С. 29-33.

Копнина Г. А., Еремина Е. В., 2015. Системность языка, экология коммуникации и гуманитарная составляющая образования: к 85-летнему юбилею профессора А.П. Сковородникова // Вестник Волгоградского государственного университета. Серия 2, Языкознание. T. 14, № 1. C. 21-29. DOI: http://dx.doi.org/ 10.15688/jvolsu2.2015.1.2.

Кушнерук С. П., 2018. Естественное и искусственное в создании текстов современной коммуникации // Вестник Волгоградского государственного университета. Серия 2, Языкознание. Т. 17, № 3. C. 16-23. DOI: https://doi.org/ 10.15688/jvolsu2.2018.3.2.

Леонтьев В. В., 2016. Грубость грубости рознь: к 20-летию исследований речевой невежливости в лингвистике // Вестник Волгоградского 
государственного университета. Серия 2, Языкознание. T. 15, № 4. C. 26-39. DOI: https:// doi.org/10.15688/jvolsu2.2016.4.3.

Майорова А. В., 2016. Языковая культура современных средств массовой информации // Филологические науки в России и за рубежом : материалы IV Междунар. науч. конф. (г. СанктПетербург, дек. 2016 г.). СПб. : Свое изд-во. C. 54-56. URL: https://moluch.ru/conf/phil/ archive/233/11364/ (дата обращения: 05.04.2019).

Серль Дж. Р., 1986. Что такое речевой акт // Новое в зарубежной лингвистике. Вып. 17. М. : Наука. С. 151-169.

Сиротинина О. Б., 2001. Основные критерии хорошей речи // Хорошая речь. Саратов : Изд-во Сарат. гос. ун-та. С. 16-28.

Сковородников А. П., 1997. Языковое насилие в современной российской прессе // Теоретические и прикладные аспекты речевого общения. Вып. 2 / отв. ред. А. П. Сковородников. Красноярск ; Ачинск : Изд-во Краснояр. ун-та. С. 10-15.

Сковородников А. П., 2008. Об элитарном типе речевой культуры // Теоретические и прикладные аспекты современной филологии : материалы ХІІІ Всерос. филол. чтений им. проф. Р. Т. Гриб (1928-1995) / науч. ред. Б. Я. Шарифуллин. Красноярск : Краснояр. гос. ун-т. С. 209-214.

Усанова О. Г., 2010. Речевая культура: проблемы и перспективы // Вестник Челябинской государственной академии культуры и искусства. Серия 3, Языкознание. № 3 (23). С. 105-108.

Фортунатов А. Н., Бокова А. В., 2014. Преодоление виртуальности. Опыт компаративного анализа социальных значений локальных сообществ в Томске и Нижнем Новгороде // Вестник Томского государственного университета. № 388 . C. 102-105. DOI: 10.17223/15617793/388/17.

Chomsky N., 1957. Syntactic Structures. Hague ; P. : Mouton. 117 p.

Chomsky N., 1965. Aspects of the theory of syntax. Cambridge : M.I.T. Press. 247p.

Droste F. G., 1977. Levels of Deviance in Linguistic Communication // Linguistics 200. N. Y. : Mouton Publishers. P. 5-25.

Hintikka K. I. J., 1971. Semantics for Propositional Attitudes // Reference and Modality / ed. by L. Linsky. Oxford : Oxford University Press. P. 158-167.

Ilyinova E.Yu., Kochetova L.A., 2016. Diachronic Perspective in Text and Discourse Studies: Review of Approaches // Вестник Волгоградского государственного университета. Серия 2, Языкознание. Т. 15, № 4. C. 18-25. DOI: https:// doi.org/10.15688/jvolsu2.2016.4.2.
LakoffG., 1971. On Generative Semantics // Semantics / ed. by D. Steinberg, L. Jacobovits. Cambridge : Cambridge University press. P. 232-296.

LinskyL., 1969. Reference and Referents // Problems in the Philology of Language / ed. by Th. M. Olshewsky. N. Y. : Mouton Publishers. P. 208-228.

Marcus R. B., 1971. Extensionality // Reference and Modality / ed. by L. Linsky. Oxford : Oxford University Press. P. 55-62.

Mates B., 1975. On the Semantics of Proper Names // Ut Videam / ed. by W. Abraham. Lisse : Peter de Ridder. P. 191-209.

McCawley, 1968. Lexical Insertion in the Transformational Grammar without Deep Structure // Papers from the CLS 4. Chicago : Chicago University Press. P. 71-80.

\section{REFERENCES}

Batsevich F.S., 2014. Kommunikativnye deviatsii i usloviya uspeshnosti rechevogo zhanra [Communicative Deviations and Circumstances of Efficiency of Speech Genres]. Zhanry rechi [Speech Genres], no. 1-2 (9-10), pp. 16-21.

Gumbolt V. fon, 1984. Izbrannye trudy po yazikoznaniyu [Selected works on linguistics]. Moscow, Progress Publ., 400 p.

Kezina S.V., 2016. Ekologicheskaya funktsiya yazyka i dukhovnaya semantika slova [Ecological Function ofLanguage and Spiritual Semantics of the Word]. Ekologia yazika i rechi [Linguistic and Speech Ecology]: proceedings of the Vth International scientific conference (Tambov, 3-5 November 2016). Tambov, Print-Servis Publ., pp. 29-33.

Kopnina G.A., Eremina E.V., 2015. Sistemnost yazyka, ekologiya kommunikatsii i gumanitarnaya sostavlyayushchaya obrazovaniya: k 85-letnemu yubileyu professora A. P. Skovorodnikova [Language consistency, ecology of communication and humanitarian constituent of education: devoted to the $85^{\text {th }}$ anniversary of professor A.P. Skovorodnikov]. Vestnik Volgogradskogo gosudarstvennogo universiteta Seriya 2, Yazikoznanie [Science Journal of Volgograd State University. Linguistics], vol. 14, no. 1, pp. 21-29. DOI: http://dx.doi.org/10.15688/jvolsu2.2015.1.2.

Kushneruk S.P., 2018. Estestvennoie i iskustvennoie v sozdanii tekstov sovremennoi kommunikatsii [Combination of Natural and Artificial Factors in Making up Modern Texts]. Vestnik Volgogradskogo gosudarstvennogo universiteta. Seriya 2, Yazikoznanie [Science Journal of Volgograd State University. Linguistics], vol. 17, no 3, pp. 16-23. DOI: https://doi.org/10.15688/ jvolsu2.2018.3.2. 
Leontiev V.V., 2016. Grubost grubosti rozn: k 20-letiyu issledovaniy rechevoy nevezhlivosti v lingvistike [ Rudeness Differs: to the 20th Anniversary of Linguistic Impoliteness Research]. Vestnik Volgogradskogo gosudarstvennogo universiteta Seriya 2, Yazikoznanie [Science Journal of Volgograd State University. Linguistics], vol. 15, no. 4, pp. 26-39. DOI: https://doi.org/10.15688/ jvolsu2.2016.4.3.

Maiorova A.V., 2016. Yazykovaya kultura sovremennykh sredstv massovoy informatsii [Linguistic Culture of Present-Day Mass Media]. Filologicheskie nauki $v$ Rossii $i$ za rubezhom: materialy IV mezhdunarodnoy nauchnoy konferentsii (Sankt-Peterburg, dekabr 2016 g.) [Philological Sciences in Russia and Abroad: proceedings of the IV International Science Conference (Saint Petersburg, December 2016)]. Saint Petersburg, Own Publishing House, pp. 54-56. URL: https://moluch.ru/conf/phil/ archive/233/11364/ (available at: 05 April 2019).

Serl J.R., 1986. Chto takoye rechevoy akt [What is a Speech Act]. Novoye v zarubezhnoy lingvistike, iss. 17. Moscow, Nauka Publ., pp. 151-169.

Sirotinina O.B., 2001. Osnovnye kriterii khoroshey rechi [Main Criteria of Good Speech]. Khoroshaya rech [Good Speech]. Sararatov, Izdatelstvo Saratovskogo gosudarstvennogo universiteta,pp. 16-28.

Skovorodnikov A.P., 1997. Yazykovoe nasilie v sovremennoy rossiyskoy presse [Linguistic Abuse in Present-Day Russian Press]. Teoreticheskie i prikladnye aspekty rechevogo obshcheniya [Theoretical and Applied Aspects of Speech Communication]. A.P. Skovorodnikov (ed.). Krasnoyarsk, Achinsk, Krasnoyarsk University Publishing House, iss. 2, pp. 10-15.

Skovorodnikov A.P., 2006. Ob elitarnom type rechevoy kultury [On the Elite Type of Speech Culture]. Teoreticheskie i prikladniie aspekti sovremennoi filologii: materialy XI filologisheskikh chteniy imeni professora R.T. Grib (1928-1995) [Theoretical and Applied Aspects of Present-Day Philology: proceedings of $13^{\text {th }}$ Philological Readings named after R.T. Grib (1928-1995). B.Ya. Sharifullin (ed.). Krasnoyarsk, Krasniyarskiy gosudarstvennyy universitet, pp. 209-214.

Usanova O.G., 2010. Rechevaia kultura: problemy i perspektivy [Speech Culture: Problems and
Perspectives]. Vestnik Chelyabenskoi gosudarstvennoi akademii kultury $i$ iskusstva. Seria 3, Yazikoznanie [Herald of the Chelyabinsk State Academy of Culture and Arts], no 3 (23), pp.105-108.

Fortunatov A.N., Bokova A.V., 2014. Preodolenie vertualnosti. Opyt komparativnogo analiza sotsialnikh znachenii lokalnikh soobschestv v Tomske i Nizhnem Novgorode [Overcoming of Virtuality. Experience of Comparative Analysis of the Social Values of Local Communities in Tomsk and Nizhny Novgorod]. Vestnik Tomskogo gosudarstvennogo universiteta [Tomsk State University Journal], no. 388, pp. 102-105. DOI: $10.17223 / 15617793 / 388 / 17$.

Chomsky N., 1957. Syntactic Structures. Hague, Paris, Mouton. 117 p.

Chomsky N., 1967. Aspects of the theory of syntax. Cambridge, M.I.T. Press. 247 p.

Droste, F.G., 1977. Levels of Deviance in Linguistic Communication. Linguistics 200. New York : Mouton Publishers, pp. 5-25.

Hintikka, K.I.J., 1971. Semantics for Propositional Attitudes. Reference and Modality. L. Linsky (ed.), Oxford University Press, pp. 158-167.

Ilyinova E.Yu., Kochetova L.A., 2016. Diachronic Perspective in Text and Discourse Studies: Review of Approaches. Vestnik Volgogradskogo gosudarstvennogo universiteta Seriya 2, Yazikoznanie [Science Journal of Volgograd State University. Linguistics], vol. 15, no. 4, pp. 18-25. DOI: https://doi.org/10.15688/ jvolsu2.2016.4.2.

Lakoff G., 1971. On Generative Semantics. Semantics. D. Steinberg, L. Jacobovits (eds.). Cambridge University press, pp. 232-296.

Linsky L., 1969. Reference and Referents. Problems in the Philology of Language. Th.M. Olshewsky (ed.). New York, Mouton Publishers, pp. 208-228.

Marcus R.B., 1971. Extensionality. Reference and Modality. L. Linsky (ed.). Oxford University Press, pp. 55-62.

Mates B., 1975. On the Semantics of Proper Names. Ut Videam. W. Abraham (ed.). Lisse, Peter de Ridder, pp. 191-209.

McCawley, 1968. Lexical Insertion in the Transformational Grammar without Deep Structure. Papers from the CLS 4. Chicago University press, pp. 71-80. 
E.И. Почтарь. Параметры оценки языковой корректности и коммуникативной успешности

\section{Information About the Author}

Elena I. Pochtar, Candidate of Sciences (Philology), Associate Professor, Theory and Practice of Translation Department, Shevchenko State University of Pridnestrovie, 25-go Oktyabrya St, 127, 3300 Tiraspol, Pridnestrovie, ent_15@rambler.ru, https://orcid.org/0000-0002-5029-1948

\section{Информация об авторе}

Елена Ивановна Почтарь, кандидат филологических наук, доцент кафедры теории и практики перевода, Приднестровский государственный университет им. Т.Г. Шевченко, ул. 25-го Октября, 127, 3300 г. Тирасполь, Приднестровье, ent_15@rambler.ru, https://orcid.org/0000-0002-5029-1948 